\title{
An Examination of Computer Attitudes, Anxieties, and Aversions Among Diverse College Populations: Issues Central to Understanding Information Sciences in the New Millennium
}

\author{
William H. Burkett \\ Palm Beach Atlantic \\ College \\ burkettw@pbacedu
}

\author{
David M. Compton \\ Palm Beach Atlantic \\ College \\ comptond@pbacedu
}

\author{
Gail G. Burkett \\ Palm Beach Community \\ College \\ griswolg@pbcacc.flus
}

\begin{abstract}
Studying the impact of computer attitudes on the production of knowledge is central to the understanding of information sciences in the new millennium. The major results from a survey of diverse college populations suggest that Liberal Arts College (LAC) students, in this demographic, have somewhat more ambivalence toward computers than students in a Community College (CC) or a nontraditional Business College $(B C)$ environment. The respondents generally agreed that computers were an important part of daily life and not particularly frustrating. In addition, it appears that today's students like computers, know at least something about them, feel competent when using one, and are not tired of hearing about computers as a matter of daily discourse. The participants generally agreed, although not strongly so, that they would like to learn more about computers. The surveyed students generally expressed an interest in on-line courses, although students from the LAC were more neutral about on-line courses. On-line courses were generally considered somewhat inferior to traditional classes. Most of the respondents feel that they have a reasonable amount of computer-related experiences and, as a result, have considerable competence and success when using one, and believed that they could successfully master new software. The majority of the students expressed at least some degree of enjoyment from computer and non-computer games. Last, students at the LAC and BC appeared to possess greater knowledge about computer operation, a fact that may in part be due to the age of the respondents.
\end{abstract}

Keywords: computer aversion, computer anxiety, computer phobia, computer avoidance, computer attitude

\section{Overview}

\section{Definitions of Computer Attitude, Anxiety, Aversion, and Avoidance}

Students' attitudes toward the various aspects of information science are manifest in varying manners and degrees. Irritation, bewilderment, frustration, and feelings of panic are emotional boundaries that many computer educators face in the academic world of today. Expressions such as computer avoidance, computer anxiety, computer aversion, and computer-phobia are used with regularity in an effort

\footnotetext{
Material published as part of this journal, either on-line or in print, is copyrighted by the publisher of Informing Science. Permission to make digital or paper copy of part or all of these works for personal or classroom use is granted without fee provided that the copies are not made or distributed for profit or commercial advantage AND that copies 1) bear this notice in full and 2) give the full citation on the first page. It is permissible to abstract these works so long as credit is given. To copy in all other cases or to republish or to post on a server or to redistribute to lists requires specific permission and payment of a fee. Contact Editor@inform.nu to request redistribution permission.
}

to categorize these emotions. These terms are ingrained in the literature of a plethora of computer based journal articles if Gordon (1995), Burkett (1993), Fletcher and Deeds (1994), Givens (1998), Tobias (1979), Fajou (1997), Bohlin (1999), and others are an example.

Fajou (1997) uses the definition of "distress or uneasiness of mind caused by apprehension of danger or misfortune" when writing of computer anxiety. Bohlin (1999) notes that "a computer anxious learner is one who is nervous, distracted, and physically and emotionally uncomfortable in the presence of or under the expectation of interacting with a computer."

\section{The Literature of Computer Attitude, Anxiety, Aversion, and Avoidance}

The literature would seem to indicate that computer anxiety leads to computer avoidance via computer aversion or computer phobia associated with various demographics (gender, age, ethnicity, etc.), at times, acting as key elements in the algorithm. According to Yang et al. (1999) "There are a number of studies on the relationship of computer experience with computer anxiety ..." They list eight 


\section{Computer Attitudes, Anxieties, and Aversions}

authors in their article for the Journal of Industrial Teacher Education that have studied demographic variables. They also list six authors that have noted direct relationships between computer-related experience and computer anxiety and four articles that examine the relationship of demographic variables and computer anxiety.

Green et al. (1993) states that "Attitudes (about computers) have been examined by several researchers..." and goes on to name five including Meier (1988), the developer of the Computer Aversion Scale (CAV), the basis for the survey conducted for this paper. Brosnan (1998) lists gender, level of experience, computer attitude, educational level, knowledge of computers, external locus of control and attitudes toward mathematics as correlates to computer anxiety and avoidance.

Numerous authors, as outlined above, have associated computer anxiety with many correlates. Demographics, computer experience (or lack of), attitude toward computers, and educational level, either directly or indirectly may lead to computer anxiety that in due course can be an advocate of computer avoidance. While the percentage of respondents indicating that they were not comfortable about using computers was small it is significant that it still is an identifiable factor.

\section{Method}

\section{Participants and College Sites}

The participants were 578 college students (216 men and 363 women) from three colleges located in southern Florida. After exclusion of incomplete surveys, the data were analyzed for a total of 565 surveys. Summary statistics for the respondents affiliated with each college site are presented in Table 1. As can be seen in this table, schoolassociated age differences were observed, $\underline{F}(2,565)=$ $38.65, \mathrm{p}<.001$. Post hoc examination (Tukey, $\mathrm{p}<.05$ ) of this observation revealed that the Business College (BC) students were significantly older $(\underline{\mathrm{M}}=27.79$ years, $\underline{\mathrm{SD}}=$ 6.93 years) than students from the other schools $(\underline{\mathrm{Ms}}=$ $22.95 \& 21.54$ years, $\underline{\text { SDs }}=7.29 \& 5.60$ years, Community College (CC) \& Liberal Arts College (LAC), respectively), which did not differ significantly.

All sites were Southern Association of Colleges and Schools (SACS) accredited and granted undergraduate degrees appropriate to their charters. School A is a 2-year state mandated community college (CC) granting an Associates degree, having a student population of 18,000, and offering the largest selection of on-line courses of the three schools under consideration. Faculty and instructors are encouraged and remunerated in an effort to develop more

\begin{tabular}{|c|c|c|c|}
\hline Demographic & $\begin{array}{c}\text { Community } \\
\text { College }\end{array}$ & $\begin{array}{l}\text { Liberal Arts } \\
\text { College }\end{array}$ & $\begin{array}{r}\text { Business } \\
\text { College }\end{array}$ \\
\hline Age (M) & 21.54 & 22.95 & 27.79 \\
\hline (SD) & 7.29 & 5.60 & 6.93 \\
\hline \multicolumn{4}{|l|}{ Gender } \\
\hline Male $(\underline{\mathbf{N}})$ & 61 & 179 & 21 \\
\hline Female $(\underline{\mathbf{N}})$ & 84 & 136 & 89 \\
\hline \multicolumn{4}{|c|}{ Computer Knowledge } \\
\hline Novice & $2.91 \%$ & $0.00 \%$ & $1.94 \%$ \\
\hline Elementary & $12.40 \%$ & $6.86 \%$ & $11.65 \%$ \\
\hline Average & $59.87 \%$ & $61.11 \%$ & $58.26 \%$ \\
\hline Professional & $21.90 \%$ & $31.05 \%$ & $27.18 \%$ \\
\hline Expert & $2.92 \%$ & $0.98 \%$ & $0.97 \%$ \\
\hline
\end{tabular}

Table 1. Summary statistics for the sample. 
courses. Only students in math remedial courses at one of four campuses were included in the survey (a population of approximately 1500). Courses are offered in Computer and Information Sciences as well as many other subjects. This is a typical community college and thus most students are commuters, though there are a limited number of dorms available. Students have computers in numerous teaching labs and the library on each campus.

School B is a 4-year individually held private business college (BC) with a limited offering in majors. The school grants both Associate and Bachelor degrees and has a population of approximately 400 students. Though material has been provided to instructors about developing online courses there has been no movement in this direction to date. Courses are offered in Computer and Information Sciences as well as Paralegal, Medical, and Business areas. There are no dorms available and all students are considered commuters. Computers are available in the two computer teaching labs and library. Students included in the survey were primarily members of classes that met in the evening.

School C is a 4-year liberal arts private college (LAC) with a wide range of majors and chartered to grant Associate, Bachelor and Masters degrees. The school has a population of 2800+ with about half living on campus. Courses are offered in Computer Science and Information Science. A limited number (12 - 14) of on-line courses are offered but there seems to be no discernible movement to increase this offering. Faculty are not remunerated or strongly encouraged to increase the on-line course offering. Students have computers in all dorm rooms, the library, and numerous teaching labs on the campus. Students included in the survey were members of day and evening classes in both the Bachelors and Masters programs from a plethora of disciplines including Arts, Education, Business, and Communications.

\section{Instrument}

The survey consisted of a series of true/false and multiplechoice questions as well as demographic items adapted from the Computer Aversion Scale (CAV; Meier, 1990). In its original form, Meier's survey assesses three factors reinforcement expectations for computers, outcome expectations for computers, and efficacy expectations for computers, respectively. Factor analysis of the present survey using Principle Components Analysis (PCA) with Varimax rotation and a three-factor solution is presented elsewhere (Compton, Burkett, \& Burkett, 2001). With the exception of the demographic items, the survey is presented in Appendix A. The survey, titled, "Affective and academic results of computer-based training and learning," took approximately 15 minutes to complete, and in addition to the adapted CAV questions, included a series of four questions designed to assess student perception of the efficacy of on- line courses. The participants were also asked demographic data related to gender, age, academic discipline, and current degree program (i.e., associates, bachelors, etc.). All surveys were completed within a one-month span in early Spring 2001 and, in the majority of instances, in the presence of the three principle authors.

\section{Scoring and Statistical Analysis}

As noted above, 13 individuals failed to complete the survey. Of these, six were from the $\mathrm{CC}$, five were from the LAC, and the remaining two were from the BC. Available data from these 13 individuals were not included in any of the univariate or multivariate analyses. Last, it is worth noting that group sample sizes were significantly different, $\chi^{2}(2)=127.99, \underline{p}<.001$.

All data were analyzed using Systat (Wilkinson, 2000). The data from the three groups was compared using chisquare or multivariate analysis of variance (MANOVA) as appropriate with the analyses arranged on the basis of the three factors described above. Thus, three MANOVAs were performed. Before the results of the multivariate analyses were interpreted, the data were examined to determine if the appropriate multivariate assumptions were met (Stevens, 1992). When the MANOVAs were significant the univariate $\underline{F}$ values were interpreted (Hummel \& Sligo, 1971; see also, Weinfurt, 1995) and followed up with post hoc comparison of the means using Tukey's procedure (Tukey, 1977).

Finally, because age differences were associated with academic institution, bivariate regression analyses were performed between all questions and age, with age as the predictor variable. Because of the number of analyses, an $\alpha$ level of .01 was chosen as the a priori criterion for significance.

\section{Conclusion}

\section{Knowledge and Perception of Computer Competency}

This study analyzed students' responses, at three campuses. Their academic disciplines were varied. The attitudes they manifested toward computers could be construed as an indicator of their degree of computer anxiety. This degree of computer anxiety, in turn, is of importance to those that will be overseeing or providing information to clients in the near future.

Approximately, $92 \%$ of CC students affirmed that they could use a word processing program for letter writing purposes. A similar percentage of $\mathrm{BC}$ students responded in the affirmative (91.07\%). However, the observed frequencies across groups was significant, $\chi^{2}(2)=14.23, \mathrm{p}<$ $.001, \varphi_{C}=.157$, with $98.42 \%$ of LAC expressing competency with word processing programs. Although group 
Computer Attitudes, Anxieties, and Aversions

differences were observed, $\chi^{2}(2)=116.01, \underline{p}<.001, \varphi_{C}=$ .167 , most of the students at each school felt that they knew how to use computer programs. However, among $\mathrm{CC}$ students, perceived competency did not extend to knowledge about basic computer hardware, as only $48.63 \%$ knew that the modem did not store the computer's memory. Similar but significantly higher knowledge levels were observed among LAC $(71.25 \%)$ and BC $(71.96 \%$ correct) students, $\chi^{2}(2)=24.95, \mathrm{p}<.001, \varphi_{\mathrm{C}}=.210$.

As can be seen in Table 1, across colleges, different patterns in perceived overall computer competency emerged, $\chi^{2}(8)=17.81, \underline{p}<.025, \varphi_{C}=.181$. Specifically, $24.84 \%$ of CC students rated themselves as computer experts or professionals, while $32.03 \%$ of LAC students and $28.15 \%$ of BC students did so. Interestingly, $15.31 \%$ of CC students and $13.59 \%$ of $\mathrm{BC}$ students (with presumably greater workplace experience) rated themselves as having elementary or novice levels of knowledge, while only $6.86 \%$ of LAC students endorsed either of these two categories. This result is consistent with an analysis of question 25 (see below, Factor I) where differences in perceived competence among the schools were observed.

The preceding is noteworthy in light of the fact that $33.6 \%$ of the sample $(\mathrm{CC}=49.7 \%, \mathrm{LAC}=28.5 \%, \mathrm{BC}=26.5 \%)$ did not know the location of memory storage. An additional analysis was performed to assess the relationship between perceived knowledge and a concrete measure of actual knowledge. In order to meet the assumptions of chisquare and address the issues associated with small expected frequencies (Spatz, 2001), the novice and elementary categories were combined, as were the professional and expert categories. Examination of these data revealed that perceived knowledge and location of where the computer's memory is stored were related, $\chi^{2}(3)=22.89, \mathrm{p}<$ $001, \varphi_{C}=.201$. Over $48 \%$ of the individuals who rated themselves as novice/elementary agreed with the statement that a modem is where the computer's memory is stored while among those with average- or professional/expert-rated knowledge, the number of incorrect respondents dropped to $36.64 \%$ and $21.38 \%$, respectively. Thus, even among those who consider themselves as competent to expert, such knowledge may not necessarily extend to the computer hardware.

\section{Factor I - Reinforcement Expectations From Computers}

The mean scores for the 15 questions that constituted Factor I are provided in Table 2. A one-way multivariate analysis of variance (MANOVA) revealed a significant effect of educational setting, Wilks' $\lambda=0.818$, approximate $\underline{\mathrm{F}}(30,1096)=3.86, \underline{\mathrm{p}}<.001$. Following this finding, the data were explored further by examining the univariate $\underline{F}$ values associated with each dependent measure. Where appropriate the univariate analyses were followed with post hoc comparison of the three groups using Tukey's procedure $(\mathrm{p}<.05)$. The primary result of these analyses revealed a difference in the internalized importance of computers.

Although all three groups generally disagreed with the statement that there were many tasks in life more important than work with computer applications (Q13), the three groups differed in terms of how strongly they held this belief, $\underline{\mathrm{F}}(2,562)=26.12, \underline{\mathrm{p}}<.001, \eta^{2}=.090$. While CC and BC students held a similar position, the LAC students were neutral about the importance of computer applications in their life.

The students at the three institutions differed in perceived level of frustration with computers (Q15), F $(2,562)=$ $8.12, \underline{p}<.001, \eta^{2}=.030$. Post hoc examination revealed that LAC and CC students were significantly more frustrated with computers than students who comprised the $\mathrm{BC}$ group. On the basis of the preceding, it was not surprising to find that the students differed in terms of their dislike for computers $(\mathrm{Q} 19), \underline{\mathrm{F}}(2,562)=3.31, \mathrm{p}<.05, \eta^{2}$ $=.014$, with CC students significantly more likely to indicate a favorable opinion than LAC students. BC students held a position intermediate between and not significantly different from students at the other two schools. However, as can be seen in Table 2, all three groups held a generally favorable view of computers, with the group differences a matter of how strongly the position was held. Although students from the three schools differed in the degree to which they were tired of hearing about computers (Q27), $\underline{\mathrm{F}}(2,562)=8.79, \underline{\mathrm{p}}<.001, \eta^{2}=.033$, only LAC students felt neutral, while $\mathrm{CC}$ and $\mathrm{BC}$ students indicated positive feelings towards messages about computers (see Table 2).

As noted above, the three groups differed in their perceived knowledge of computers $(\mathrm{Q} 25), \underline{\mathrm{F}}(2,562)=3.21, \mathrm{p}$ $<.05, \eta^{2}=.013$. In light of the above it was interesting that $\mathrm{CC}$ students perceived themselves as significantly less knowledgeable (Q33) than LAC or BC students, who held similar perceptions. Although significant group differences were observed, $\underline{\mathrm{F}}(2,562)=3.69, \mathrm{p}<.05, \eta^{2}=.011$, students in all three groups felt that they knew something about how a computer operates (Q33). However, the position of the LAC students was less firm than that of the other two groups, where the latter two did not differ. While the students from all three schools believed that they were capable of using a computer without help present (Q30), they once again differed in terms of how firmly they held this belief, $\underline{\mathrm{F}}(2,562)=3.41, \underline{\mathrm{p}}<.05, \eta^{2}=.012$. BC students were significantly more likely to disagree with this statement than CC students. The position of the LAC students was once again intermediate but not significantly different from either extreme (see Table 2). Last, although the groups did differ in terms of their perceived appear- 


\begin{tabular}{|c|c|c|c|}
\hline $\begin{array}{l}\text { Factor } \\
\text { Question }\end{array}$ & $\begin{array}{c}\text { Community } \\
\text { College }\end{array}$ & $\begin{array}{l}\text { Liberal Arts } \\
\text { College }\end{array}$ & $\begin{array}{l}\text { Business } \\
\text { College }\end{array}$ \\
\hline & $\mathbf{M}(\mathbf{S D})$ & M(SD) & M(SD) \\
\hline \multicolumn{4}{|l|}{ Factor I } \\
\hline 13 & $3.09(1.62)^{b}$ & $3.94(1.65)^{\mathrm{a}, \mathrm{c}}$ & $2.80(1.59)^{b}$ \\
\hline 15 & $2.77(1.39)^{b, c}$ & $2.99(1.51)^{\mathrm{a}, \mathrm{c}}$ & $2.34(1.39)^{a, b}$ \\
\hline 19 & $1.89(1.22)^{b}$ & $2.21(1.48)^{\mathrm{a}}$ & $1.95(1.34)$ \\
\hline 25 & $3.35(1.72)^{\mathrm{c}}$ & $2.99(1.46)$ & $2.94(1.61)^{a}$ \\
\hline 27 & $2.76(1.54)^{b}$ & $3.30(1.67)^{\mathrm{a}, \mathrm{c}}$ & $2.69(1.51)^{b}$ \\
\hline 30 & $2.39(1.59)^{\mathrm{c}}$ & $2.14(1.22)$ & $1.97(1.21)^{\mathrm{a}}$ \\
\hline 31 & $1.97(1.22)$ & $2.02(1.73)^{c}$ & $1.57(0.99)^{b}$ \\
\hline 33 & $2.52(1.38)^{b}$ & $2.99(1.34)^{\mathrm{a}, \mathrm{c}}$ & $2.08(1.19)^{b}$ \\
\hline \multicolumn{4}{|l|}{ Factor II } \\
\hline 9 & $5.88(1.29)^{b}$ & $5.48(1.29)^{\mathrm{a}}$ & $5.67(1.27)$ \\
\hline 20 & $5.08(1.63)^{b}$ & $4.62(1.63)^{\mathrm{a}, \mathrm{c}}$ & $5.27(1.77)^{b}$ \\
\hline 21 & $3.48(1.39)^{b}$ & $3.04(1.39)^{\mathrm{a}, \mathrm{c}}$ & $3.53(1.35)^{b}$ \\
\hline 24 & $3.86(1.78)^{b, c}$ & $3.08(1.78)^{a, c}$ & $4.30(1.77)^{a, b}$ \\
\hline 28 & $4.00(1.36)^{b}$ & $4.36(1.37)^{\mathrm{a}, \mathrm{c}}$ & $3.77(1.36)^{b}$ \\
\hline \multicolumn{4}{|l|}{ Factor III } \\
\hline 8 & $5.01(1.36)^{b}$ & $5.40(1.36)^{\mathrm{a}}$ & $5.32(1.31)$ \\
\hline 14 & $4.65(1.53)^{b}$ & $5.10(1.53)^{a}$ & $5.04(1.58)$ \\
\hline 18 & $5.06(1.57)^{b, c}$ & $5.65(1.58)^{a}$ & $5.68(1.41)^{a}$ \\
\hline 23 & $5.21(1.41)$ & $5.19(1.41)^{c}$ & $5.54(1.20)^{b}$ \\
\hline 26 & $5.16(1.56)^{b}$ & $4.71(1.56)^{a}$ & $4.79(1.61)$ \\
\hline 35 & $4.01(1.45)^{b}$ & $4.84(1.45)^{\mathrm{a}, \mathrm{c}}$ & $4.01(1.42)^{b}$ \\
\hline
\end{tabular}

Notes. $a=$ significantly different $(p<.05)$ from CC students; $b=$ significantly different $(p<$ $.05)$ from LAC students; $c=$ significantly different $(p<.05)$ from BC students; $d=$ Only questions where significant differences between or among institutions are presented; e) $\underline{N}=145$; $f$ ) $\underline{\mathbf{N}}=310 ; \mathrm{g}) \underline{\mathbf{N}}=110$.

Table 2. Summary statistics for the survey questions

ance when using a computer $(\mathrm{Q} 31), \underline{\mathrm{F}}(2,562)=3.73, \underline{\mathrm{p}}<$ $.025, \eta^{2}=.012$, with BC holding a significantly stronger stance than the students from the LAC, students at all three colleges felt that they would appear competent when using computers.

\section{Factor II- Outcome Expectations From Computers}

The mean scores and standard deviations for the 7 questions comprising Factor II are provided in Table 2. Multivariate analysis of the data with a one-way MANOVA revealed a significant effect of educational setting, Wilks' $\lambda=0.869$, approximate $\underline{\mathrm{F}}(14,1106)=5.76, \underline{\mathrm{p}}<.001$. Examination of the univariate $F$ values associated with each dependent measure and post hoc comparisons using 
Tukey's procedure $(\mathrm{p}<.05)$ revealed information of particular use to curriculum planners.

The students at all three schools agreed that they needed to learn more about using a computer (see Table 2, Q9), although school differences were detected, $\underline{F}(2,559)=4.53$, $\mathrm{p}<.025, \eta^{2}=.013$. Post hoc examination of the means revealed that LAC students were somewhat more confident of their current skill level than CC students. BC students endorsed a position intermediate and not significantly different from either extreme.

Although their mean positions were close to neutral, students from the three schools differed in their positions toward on-line courses, $\underline{\mathrm{F}}(2,559)=8.04, \mathrm{p}<.001, \eta^{2}=$ .026 , with LAC students holding a significantly more unfavorable opinion of such courses than students from the other schools (Q21). Although students from the three schools differed in terms how strongly they felt they would take on-line courses (Q20), $\underline{\mathrm{F}}(2,559)=6.87, \mathrm{p}<$ $.001, \eta^{2}=.023$, only students at the LAC held a significantly different, although neutral, position $(\mathrm{p}<.05)$, while students at the other two schools expressed at least a marginal interest (ps $>.05)$. However, although differences among the schools were observed, $\underline{F}(2,559)=9.09$, $\underline{p}<$ $.001, \eta^{2}=.029$, students at all three schools were essentially neutral (see Table 2) about the effectiveness of online courses (Q28).

Students at the three schools differed significantly in terms of their preference for working with computers versus people, $\underline{\mathrm{F}}(2,559)=25.24, \underline{\mathrm{p}}<.001, \eta^{2}=.081(\mathrm{Q} 24)$. While all three schools held significantly different attitudes on this statement (ps <.05), only the mean response of the BC students was higher than $4.00(\underline{\mathrm{M}}=4.30)$, the neutral position suggesting a slight preference for machine over human contact. This result may be due to the greater work experience of the average BC student and is worthy of further examination. Overall it appears that the college students generally are open about course work requiring a computer with minimal human interaction.

\section{Factor III - Efficacy Expectations For Com- puters}

A one-way multivariate analysis of variance (MANOVA) of the data constituting Factor III revealed a significant effect of educational setting, Wilks' $\lambda=0.828$, approximate $\underline{F}(16,1106)=6.83, \underline{p}<.001$. The summary statistics associated with this analysis are provided in Table 2. Further exploration of the effect of educational setting by examining the univariate $\underline{F}$ values associated with each dependent measure and followed up with post hoc comparison of the three groups using Tukey's procedure $(\mathrm{p}<.05)$ suggested perceptual discrepancies as noted below.
School-related differences in perceived competence when using a computer $(\mathrm{Q} 14)$ were observed, $\underline{\mathrm{F}}(2,560)=4.84$, $\mathrm{p}$ $<.01, \eta^{2}=.017$, with CC students having felt significantly less competent than students from the other two schools, who did not differ significantly. This result may be due, in part, to a perceived amount of computer experience (Q8), $\underline{\mathrm{F}}(2,560)=4.41, \mathrm{p}<.025, \eta^{2}=.015$, as CC students endorsed a position significantly lower than students at the other two schools. Nonetheless, students from all three schools indicated that they used computers successfully as part of their daily routine (Q18), although LAC and BC students endorsed a significantly higher level of agreement than CC students, $\underline{F}(2,560)=9.60, \mathrm{p}<.001, \eta^{2}=.033$ (subsequent Tukey tests, ps $<.05$ ). Although significant group differences were observed, $\underline{\mathrm{F}}(2,560)=3.16, \underline{\mathrm{p}}<$ $.05, \eta^{2}=.011$, all students generally felt that they could learn to use new software (Q23), although LAC students endorsed a less confident position than BC students ( $\mathrm{p}<$ .05). Interestingly, $\mathrm{CC}$ students were significantly more likely to agree with the statement that they like computer games $(\mathrm{Q} 26)$ than LAC students $(\underline{F}(2,560)=3.75, \mathrm{p}<$ $.025, \eta^{2}=.018$; demonstrated by the subsequent Tukey test for this comparison, $\mathrm{p}<.05$ ); BC students were intermediate and somewhat more neutral about computer games (see Table 2). However, significant differences in interest in non-computer games were detected, $\underline{F}(2,560)=$ $23.86, \mathrm{p}<.001, \eta^{2}=.076$, with LAC students somewhat more likely to express such an interest than $\mathrm{CC}$ and $\mathrm{BC}$ students who did not differ. Nonetheless, all the students were essentially neutral about non-computer-based games, with observed differences a matter of degree.

As noted earlier, students from all three schools held positions about on-line courses that were close to neutral, although school-associated differences were detected. Further analysis suggested that LAC students hold a significantly more unfavorable opinion of such courses than students from the other schools. To reiterate, although students from the three schools differed in terms of how strongly they felt they would take on-line courses, only students at the LAC held a significantly different, (although essentially) neutral position. Students at the other two schools expressed at least a marginal interest. Although differences among the schools were observed, students at all three schools were essentially neutral (see Table 2) about the effectiveness of on-line courses (see Q28). However, it is noteworthy that only a small percentage of the students at each college had enrolled in an on-line course, with $12.42 \%$ the highest percentage at the LAC. Similar, although somewhat lower, percentages were observed at the $\mathrm{CC}(8.05 \%)$ and the $\mathrm{BC}(6.25 \%)$ but overall no differences as a function of college were observed, $\chi^{2}(2)=4.38, \underline{p}>.10, \varphi_{C}=.087$. 


\begin{tabular}{|lllll|}
\hline Question & $\underline{\mathbf{r}}$ & $\underline{\mathbf{t}}$ & $\underline{\mathbf{N}}$ \\
\hline 13 & -.188 & .001 & -4.55 & 566 \\
\hline 14 & .108 & .01 & 2.57 & 564 \\
\hline 22 & -.132 & .005 & -3.17 & 564 \\
\hline 24 & .112 & .01 & 2.67 & 567 \\
\hline 27 & -.129 & .005 & -3.09 & 567 \\
\hline 31 & -.137 & .001 & -3.28 & 567 \\
\hline 34 & -.139 & .001 & -3.34 & 564 \\
\hline 35 & -.170 & .001 & -4.09 & 566 \\
\hline
\end{tabular}

Notes. ${ }^{\text {a }}$ For each analysis, age was the predictor variable; the survey question was the criterion. bonly analyses with significant $(\underline{p}<.01$, two-tailed test) results are presented here.

\section{Table 3. Regression analyses for the 35 survey questions ${ }^{\text {a,b }}$}

\section{Age and Perception of Computers}

The significant bivariate regression analysis, with age as the predictor and each dependent measure from the questionnaire as the criterion, is presented in Table 3. Significant positive associations between age and competence (Q14), $\underline{\mathrm{r}}=.108, \mathrm{p}<.005$, as well as age and, when compared to people, the level of enjoyment working with computers $(\mathrm{Q} 24), \underline{\mathrm{r}}=.112, \mathrm{p}<.01$, were observed. Significant inverse relationships were observed between age and the relevance of computer tasks in life $(\mathrm{Q} 13), \underline{\mathrm{r}}=$ $.188, \mathrm{p}<.001$, wavering between wanting to learn about computers and avoiding them $(\mathrm{Q} 22), \underline{\mathrm{r}}=-.132, \mathrm{p}<.005$, fatigue associated with hearing about computers $(\mathrm{Q} 27), \underline{\mathrm{r}}=$ $-.129, \mathrm{p}<.005$, looking like a fool when using one (Q31), $\underline{\mathrm{r}}=-.137, \mathrm{p}<.001$, interest in computers primarily as a work-related tool $(\mathrm{Q} 34), \underline{\mathrm{r}}=-.139, \mathrm{p}<.001$, and enjoyment of non-computer based games (Q35), $\underline{\mathrm{r}}=-.170, \underline{\mathrm{p}}<$ .001 . Thus, age accounts for $3.5 \%$ of the variance or less in each of these dependent measures. Nonetheless, these results suggest that the older students held somewhat more favorable attitudes toward computers and their place in the life of the respondents.

\section{References}

Bohlin, R.M. (1999). Avoiding computer avoidance. Paper presented at California State University, Fresno, CA. [On-line September 2000] nttp://techt.coe.uga.edu/tiorum/paper35/paper35.htmा
Brosnan, M.J. (1998). The impact of psychological gender, genderrelated perceptions, significant others, and the introducer of technology upon computer anxiety in students. Journal of Educational Computing Research. V18n1. 63-78

http://ctiwebst.ork.ac.uk/LISNCIPAbstracts/CIP96CD/BR OSNANATIMATAPER.HTM

Burkett, W.H. (1993). A study of computer aversion factors and their effect on an older adult population's computer anxiety. Unpublished Dissertation report to Nova University. http://faculty.pbac.edu/burkettw/diss_whb.htm

Compton, D., Burkett, W. H., \& Burkett G.G (2001). Factor structure of the adapted Computer Aversion Survey (CAV) of Meier, 1990. Ettp://faculty.pbac.edu/Callisto/Research/Factor_1.htmi

Fajou, S. (1997). Computer Anxiety. Paper presented to the Faculty of Education University of Sydney. חtp://Www.edfac.usyd.edu.au/projects/comped/Fajou.htm

Fletcher, W.E. \& Martin, B. (1990). Dealing with computer aversion: Prescriptive strategies. Association for Educational Communications and Technology Annual Conference, Anaheim, CA, January, 1990.

Givens, D.B. (1998). AMYGDALA. Center for Nonverbal Studies, ntip:/members.aol.com/nonverbal/amygdala.htm

Gordon, H.R. (1995). Analysis of thecomputer anxiety levels of secondary technical education teachers in West Virginia. Journal of Studies in Technical Careers, 15, 21-29.

Green, K.E., and Kluever, R.C., Lam, T.C.M., Staples, C.I., and Hoffman, E.R. (1993). The effects of computer instruction on attitudes toward computers and computer-related teaching skills. Journal of Technology and Teacher Education. V1n4. http://www.coe.un.edu/elec_pub/jtate/vin48.htm 
Hummel, T. J., \& Sligo, J. R. (1971). Empirical comparison of univariate and multivariate analysis of variance procedures. Psychological Bulletin, 76, 49-57.

Meier, S.T. (1988). Predicting individual differences in performance on computer-administered tests and tasks: Development of the Computer Aversion Scale. Computers in Human Behavior, 4, 175-187.

Meier, S. T. (1990). Construct validity of an instrument designed to measure computer aversion. Presented at the 1990 annual convention of the American Psychological Association. ED328569.

Morahan-Martin, J. (1998). Women and girls last: Females and the internet. Proceedings of the IRISS ' 98 conference. nttp://WwW.S0sig.ac.uk/iriss/papers/papers5.htm

Stevens, J. (1992). Applied multivariate statistics for the social sciences $2^{\text {nd }}$ ed.). Hillsdale, NJ: Erlbaum.

Tobias, S. (1979). Anxiety research in educational psychology. Journal of Educational Psychology. 71, 573-582.

Tukey, J. (1977). Exploratory data analysis. Reading, MA: AddisonWiley.

Weinfurt, K. P. (1995). Multivariate analysis of variance. In L. G. Grimm \& P. R. Yarnold (eds.), Reading and understanding multivariate statistics (pp. 245-276). Washington: American Psychological Association.

Wilkinson, L. (2000). Systat (version 9.0). Chicago: SPSS, Inc.

Yang, H.H., Mohamed, D., and Beyerbach, B. (1999). An investigation of computer anxiety among vocational-technical teachers. Journal of Industrial Teacher Education. 37/1. nttp://scholar.ilb.vt.edu/ejournals/JTTE/v37n//yang.htm!

\section{Biographies}

William Burkett serves as Chair and Assistant Professor of Computer Information Systems at Palm Beach Atlantic College and is president of the Palm Beach Atlantic College chapter of Sigma Beta Delta (National Honor Society in Business, Management, and Administration). He is active in research in computer anxiety, older adults, computer based training and learning, and robotics. Formerly, he was Systems Manager, State of Florida, Marine Supervisor of Offshore Seismic Vessels, and Safety Engineer, Teledyne Exploration, Inc., and Petty Officer, United States Coast Guard. He is a member of the Association for Computing Machinery, American Association for Artificial Intelligence, and Association of Information Technology Professionals.

David Compton is Chair and Associate Professor of Quantitative Methods at Palm Beach Atlantic College. He served as director of the Office of Academic Research, with oversight governing all human and animal research activities. He has presented at conferences and published a number of articles in referred journals in such diverse areas as education, neuroscience, aging, neuropsychology, and contemporary social issues.

Gail Burkett is an Associate Professor of CPI Math at Palm Beach community College and serves as Cluster Chair of Palm Beach Community College CPI and is active in the development and implementation of the Center for Personalized Instruction, mathematics program. Formerly she was Educational Program Manager, State of Florida, and Chapter President of the Florida Council on Crime and Delinquency, and presented with the Correctional Educational Directors Award, 1989. She is active in research in computer anxiety, computer based training and learning, and math pedagogy, and is a member of the Florida Developmental Education Association, Florida Association of Community Colleges, and United Faculty of Florida.

\section{Appendix A}

For each statement, circle either True or False.

1. I have taken/completed at least one on-line college course.

2. I can use word processing software to write a letter.

3. I have taken college level on-line course(s).

4. I know how to use computer programs.

5. A computer modem is where the computer's permanent memory is stored.

From the options provided, please circle the most appropriate response. 
6. Computers seem 'anti-human' to me.

7. If I were sitting before a computer, I would not know how to use it.

8. I have a fair amount of computer experience.

9. I would like to learn to better use a computer.

10. Computer terminology seems like a foreign language to me.

11. I feel more competent with computers than most other people.

12. Computers have no place in my life.

13. There are many more important tasks in my life than working with computer applications.

14. I feel competent when I try to use a computer.

15. I find using a computer very frustrating.

16. I avoid computers as much as possible.

17. Computers can't help me solve any really important problems.

18. I am successfully using a computer in my daily routines.

19. I dislike computers.

20. I would take advantage of on-line courses if offered in my field.

21. On-line courses are more effective than traditional courses.

22. I waver between trying to learn about computers and avoiding them.

23. I could learn to use a new type of software I hadn't seen before.

24. Computers are often more enjoyable to work with than people.

25. Compared to other people, I know very little about computers.

26. I enjoy computer games.

27. I am tired of hearing about computers.

28. My school should offer online courses for basic requirements.

29. On-line courses are less effective than traditional courses.

30. The only way I would use a computer is if someone told me I had to do it.

31. I would look like a fool if I tried to use a computer.

32. On-line courses are too expensive for what you receive.

33. I have very little sense of how a computer operates.

34. I am more interested in learning about computer applications mostly geared towards practical, at-home use (e.g., simple bank account management) than computer applications mostly geared towards business and industry use (e.g., spreadsheets).

35. I enjoy non-computer based games.

From the options provided, please circle the most appropriate response.

How do you rate your general knowledge I background of computer operations I applications (such as Windows, games, word-processing \& spreadsheet) usage?

Novice

Elementary

Average

Professional

Expert 